\title{
Chromatography-based on- and in-line pre-concentration methods in capillary electrophoresis
}

\author{
L. Saavedra, C. Barbas* \\ Sección de Química Analítica, Facultad de Farmacia, Universidad San Pablo-CEU, Campus Montepríncipe, 28668 Boadilla del Monte, Madrid, Spain
}

Received 19 June 2006; accepted 6 November 2006

\begin{abstract}
Capillary electrophoresis (CE) poses unique challenges in many different analytical applications, mainly to biological and complex samples and when only small amounts of sample are available, due to its low sample consumption. As a consequence, poor limits of detection are usually observed with this technique, especially with UV photodetectors. Minimal or no sample treatment is desirable in any analytical method to avoid external sources of contamination or errors and to provide a high throughput. On- and in-capillary sample pre-concentration strategies, based on solid-phase extraction (SPE) technology can take advantage of both techniques (SPE and CE), while avoiding sample contamination and tedious manipulations when the sample amount is an issue. Moreover, the combination can provide two-dimensional separations. This review collects the most recent strategies that merge SPE technology built on- and in-capillary pre-concentration for increasing sensitivity and/or selectivity.
\end{abstract} (C) 2006 Elsevier B.V. All rights reserved.

Keywords: Solid-phase extraction; Membrane; Sample pre-concentration; Clean-up; Capillary electrophoresis

\section{Contents}

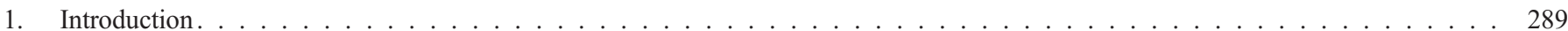

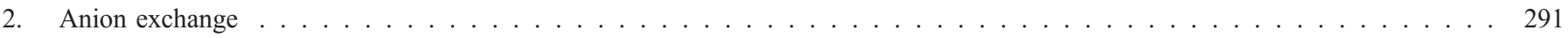

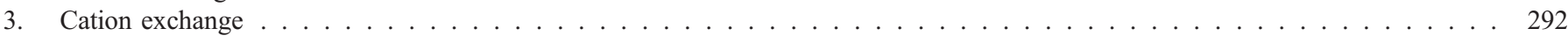

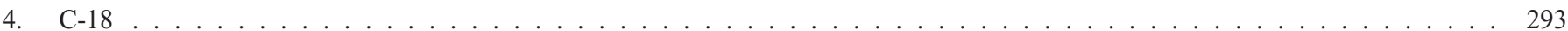

5. Immuno-affinity . . . . . . . . . . . . . . . . . . . . . . . . . . . . . 293

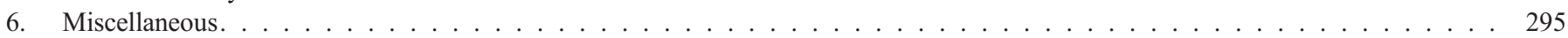

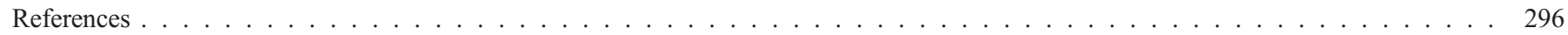

\section{Introduction}

Capillary electrophoresis (CE) offers unique challenges for the development of simple analytical methods with highly efficient separations and minute consumption of both sample and reagents, sensitivity being the main drawback. This is why strategies for integrating sample pretreatment with chemical analyses in a single process are required for rapid and sensitive analyses of low-abundance metabolites in complex samples. Pre-concentration can be performed manually (off-line), via

\footnotetext{
* Corresponding author. Fax: +34 913510475.
}

E-mail address: cbarbas@ceu.es (C. Barbas). connecting tubes that transport a stream of liquid directly to the CE set-up (on-line) or are fully integrated in the CE set-up (inline). The on- and in-line combinations of pre-concentration with the $\mathrm{CE}$ separation enable a significantly faster analysis than off-line combinations. These methods can be classified into electrophoresis-based and chromatography-based pre-concentration, depending on whether they are based on differences in analyte velocity or analyte sorption in a solid phase. There are three main electrophoretic pre-concentration mechanisms: sample stacking, field-amplified injection, and isotachophoresis. All have been extensively and frequently reviewed elsewhere.

While electrophoretic stacking can be used to load larger amounts of sample into the CE capillary, it is difficult to fill 
more than half of the column volume without diminishing the effective separation length of the capillary and creating artifacts that vitiate the $\mathrm{CE}$ separation process. In contrast, it is possible to load multiple column volumes into a $\mathrm{CE}$ capillary equipped with a chromatographic cartridge and concentrate the analytes several-fold with minimal adverse effect on the CE separation process.

On-column chromatographic concentration was first introduced by Guzman et al. [1]. A review by Veraart et al. [2], dealing with biological sample handling and CE, established a clear classification of the existing sample preparation/pre-concentration techniques used with biological samples prior to CE. Specific on-line solid-phase pre-concentration methods for capillary electrophoresis were reviewed by Bonneil and Waldron [3]. Later, Osbourn et al. [4] published a more general review of on-line pre-concentration methods in CE, including electrophoretic procedures. In 2001, Guzman and Stubbs [5] reviewed online sample pre-concentration and micro-reaction in capillary electrophoresis with selective adsorbents, based on chemical or biological specificity. Stroink et al. [6] reviewed the large arsenal of pre-concentration methods for peptides and proteins. Additionally, principles and applications for techniques, such as supported-liquid membrane extraction, micro-porous membrane liquid/liquid extraction, polymeric membrane extraction, and membrane extraction with a sorbent interface have been reviewed previously [7]. This review focuses on chromatography-based on- and in-line pre-concentration methods (both terms are frequently wrongly interchanged), updating previous reviews and covering aspects not covered in them.

For most of these studies, a solid-phase extraction (SPE) cartridge was prepared, in which the solid packing material was retained in the capillary by two fritted disks. An alternate packing material, i.e., a polymeric membrane impregnated with a chromatographic stationary phase, such as C-18, was also used. Membrane-based SPE devices do not require the use of retainers to hold the chromatographic material in place. Alternatively, open-tubular columns with the adsorbent/bonding compound attached to the wall and hollow fibers have also been applied. In our experience, the retaining frits cause problems when high resolution is needed. Back-pressure will build up and necessitate the use of an external pressure source in order to move the background electrolyte (BGE) inside the capillary. Otherwise the driving force of the electric field may not be sufficient to overcome the back-pressure resistance. In such cases, the parabolic flow-profile, typical for hydrodynamically driven separations, yields to a general peak broadening and consequent loss of efficiency. The analyte retention/desorption mechanism may be another source of peak broadening. The selectivity of SPE-based pre-concentrators is due to differences in affinity of the analytes for the two phases, regardless the actual mechanism in each case [strong-anionic exchange (SAX), strong-cationic exchange (SCX), mixed modes, or interaction with C-18]. These transitions are governed by the corresponding equilibrium constants, so that the higher the constant is the more compact the peak will be, due to quick desorption from the SPE sorbent into the separation buffer or solvent. Poor efficiency in the desorption step may result in peak fronting or tailing and a
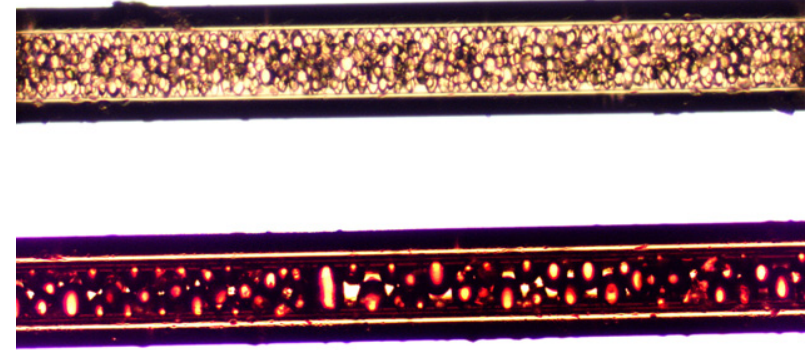

Fig. 1. Optical images $(4 \times)$ of capillaries, packed with two different particle sizes. Top: A $150-\mu \mathrm{m}$ i.d. capillary, filled with Waters OASIS MCX sorbent (average particle size, $30 \mu \mathrm{m}$ ). Bottom: A $150-\mu \mathrm{m}$ i.d. capillary, filled with Waters OASIS MCX sorbent (average particle size, $60 \mu \mathrm{m}$ ).

loss of Gaussian shape. This is an intrinsic property of each analyte/sorbent/solvent combination and is not necessarily a problem. However, in our experience, it is something to be considered and, of course, one the parameters to be optimized.

Particle size may play a similar role in the pre-concentration process as in the chromatographic column. In that regard, a higher bead diameters lead to a decreased back-pressure but also a loss in packing efficiency, resulting in a lower load capacity. On the other hand, smaller particles can be packed much easier into the capillary and provide a larger active surface for the retention process. Fig. 1 shows two different capillaries, packed in our laboratory with $30-$ and $60-\mu \mathrm{m}$ average particle size, respectively, under a $4 \times$ optic microscope.

An on-/in-capillary pre-concentration system must consist of two distinct steps. Firstly, the sample loading step, leading to pre-concentration of the target analytes in the pre-concentration chamber, and secondly, the analyte release step, followed by the separation itself. If these two processes are carried out simultaneously, the technique, in our opinion, should be considered to be electrochromatography, independent of the mechanism of the separation.

Innovation in the CE pre-concentration technology does not reduce everything to the construction of small in-capillary SPE chambers with different materials or frits. Nowadays, several techniques have become available for overcoming some of the problems that have plagued earlier devices. At this point, Guzman's work, [8-10] must be mentioned. He has developed a multi-channel immuno-affinity capillary electrophoresis (IACE) system, in which different capillaries, each one with a specific immobilized antibody, are set up in a parallel configuration. In this technique, the sample is loaded transversally with a T-valve that allows the flow-direction to be controlled. All capillaries merge into one, prior to the detection window. This simplifies the detection process, allowing one detector to collect multiple signals from several capillaries. This methodology implies the existence of different mobilities for the target analytes in order to separate their peaks (assuming the same length for all capillaries). This IACE set-up increases the applicability of this technology and provides high selectivity, due to the highly specific antibody/antigen interactions, without decreasing the number of compounds to be tested in a single run. 
Table 1

Summary of the most recent methods that use SPE/CE technology for sensitivity enrichment

\begin{tabular}{|c|c|c|c|c|c|}
\hline Analyte & Sample & Interaction & Pre-conc. factor & $\begin{array}{l}\text { Detection/LOD } \\
\text { achieved }\end{array}$ & Reference \\
\hline Inorganic anions & Antartic ice & R-NR ${ }_{4}^{+}(\mathrm{SPE})$ & 100 & $\mathrm{UV} /<\mathrm{ppb}$ & [12] \\
\hline Organic anions & Standards & AS18 latex polymer (R-NR 4 ) & $581-10400$ & $\mathrm{UV} / 1.5-12 \mathrm{nM}$ & [15] \\
\hline Inorganic anions & Seawater & $\begin{array}{l}\text { Monolithic polymer anion-exchange } \\
\text { device }\end{array}$ & 21 & $\mathrm{UV} / 75 \mathrm{pM}$ & [16] \\
\hline Alkline-earth metal ions & Standards & Dual-layer ion-exchange & & $\mathrm{UV} / \mu \mathrm{M}$ & [17] \\
\hline Propanolol and metoprolol & Standards & $\begin{array}{l}\text { Carboxyl cation exchange SPE/CE } \\
\text { via T-joint interface }\end{array}$ & 5000 & $\begin{array}{l}\mathrm{UV} / 0.02 \text { and } 0.1 \mu \mathrm{g} / \mathrm{L} \text {, } \\
\text { respectively }\end{array}$ & [18] \\
\hline $\begin{array}{l}\text { fas-F, angiotensin I, oxytocin, } \\
\text { bradykinin, LHRH }\end{array}$ & $\begin{array}{l}\text { Synthetic } \\
\text { peptides }\end{array}$ & C-18 & $200-380$ & $\mathrm{UV} / 1-5 \mathrm{ng} / \mathrm{mL}$ & [19] \\
\hline Progesterone and $\beta$-estradiol & Standards & $\mathrm{C}-18$ & $\sim 200,>600$ (non-linear) & LIF & [37] \\
\hline Enkephalin & Standard & C-18 (T-split inteface) & 200 & $\mathrm{UV} / 5 \mathrm{ng} / \mathrm{L}$ & [20] \\
\hline $\operatorname{IgG}$ & Serum & $\begin{array}{l}\text { Protein G, linked to monolithic } \\
\text { structure }\end{array}$ & & $\mathrm{UV} / 960 \mathrm{pM}-1.4 \mathrm{nM}$ & [27] \\
\hline Ibuprofen and naproxen & Urine & Fab' antibody fragments (IACE) & & $\mathrm{UV} / 1 \mathrm{ng} / \mathrm{mL}$ & [28] \\
\hline Angiotensin II and neurotensin & Urine & Fab' antibody fragments (IACE) & & $\mathrm{UV} / 0.5 \mathrm{ng} / \mathrm{mL}$ & [28] \\
\hline Cytokines & Cerebrospinal fluid & $\begin{array}{l}\mathrm{F}(\mathrm{ab})_{2} \text { fragments linked to } \\
\text { the surface (IACE) }\end{array}$ & & $\mathrm{LIF} / 0.6-1.5 \mathrm{pM} / \mathrm{mL}$ & [30] \\
\hline Angiotensin II and gonadorelin & Standards & $\mathrm{DVB} / \mathrm{SPE}$ & $3-4$ & $\begin{array}{l}\mathrm{UV} / 20 \mathrm{pg} \text { for } 20 \mu \mathrm{L} \\
\text { injection }\end{array}$ & [31] \\
\hline Angiotensin II and gonadorelin & Plasma & $\mathrm{DVB} / \mathrm{SPE}$ & $3-4$ & $\mathrm{UV} / \mathrm{nM}$ & [32] \\
\hline Angiotensin II and gonadorelin & Standards & $\begin{array}{l}\text { Non-specific hydrophobic } \\
\text { interactions }\end{array}$ & 3 & $\mathrm{MS} / \mathrm{nM}$ & [33] \\
\hline Tricyclic antidepressants & Urine & $\begin{array}{l}\text { Fiber-in-tube SPME with phenyl- } \\
\text { polydimethylsiloxane }\end{array}$ & $\begin{array}{l}39-143 \text {, depending on the } \\
\text { extraction solvent }\end{array}$ & $\mathrm{UV} / 44-153 \mathrm{ng} / \mathrm{mL}$ & [34] \\
\hline Amino acids & Standards & $\begin{array}{l}\text { Charged sol/gel extraction } \\
\text { (C-18-TMS) }\end{array}$ & up to 150,000 & $\mathrm{UV} / \mathrm{up}$ to $23 \mathrm{nM}$ & [35] \\
\hline Fluorescein and FITC & Standards & Liquid-phase micro-extraction & 3 orders of magnitude & LIF & [36] \\
\hline R-phycoerythrin & & $\begin{array}{l}\text { Imprinted membrane coupled to } \\
\text { micro-devices }\end{array}$ & up to 10,000 & Fluorescence detection & [11] \\
\hline $\begin{array}{l}\text { Cytochrome } c \text {, lysozyme, } \\
\text { ribonuclease, and } \\
\text { chymotrypsinogen }\end{array}$ & Standards & Cellulose acetate-coated porous joint & up to 800 & & [38] \\
\hline BSA & Standard & $\begin{array}{l}\text { Size-exclusion with cellulose acetate } \\
\text { membrane }\end{array}$ & 550 & UV at $214 \mathrm{~nm}$ & [39] \\
\hline Flavonoids & Standards & $\mathrm{C}-18$ & & UV & [24] \\
\hline Peptides or glycopeptides & & $\mathrm{C}-18$ & & MS/high picomolar & [23] \\
\hline
\end{tabular}

Another area worthy of attention is the so called lab-on-a-chip or microchip technology. These devices have become quite popular, mainly due to their low sample consumption, fast analysis times, and integration with other micro-fluidic capabilities. However, the limit of detection (LOD) of on-chip $\mathrm{CE}$ systems can be limited by the small sample volumes and the shallow depth of the etched channels (typically 10-20 $\mu \mathrm{m}$ ), which limits the path-length available to photodetectors. Electrophoretically based pre-concentration methods, such as stacking techniques, field-amplified injection, and isotachophoresis (ITP), have been successfully applied, and examples have been recorded in the literature. However, to our knowledge, there are not many examples of chromatography-based on-chip methods for improving the sensitivity of such devices. Kelly et al. [11] have summarized the state of the art in this area.

In analogy with traditional CE pre-concentration devices, these studies will be classified according to the mechanism of interaction between the analyte and the adsorbent/bonding group. Table 1 summarizes the most relevant recent applications according to the retention mechanism in each case, and they are discussed below.

\section{Anion exchange}

While some authors have opted for electrophoretic and some for chromatographic modes of pre-concentration, a very elegant approach is to combine the best of both modes in the same run. That has been one of the aims of Haddad group [12-14]. They have developed an on-capillary pre-concentration method for the $\mathrm{CE}$ determination of inorganic anions, based on anionexchange solid-phase extraction and transient isotachophoretic gradient elution. The capillary for this contains a preconcentration zone (the coated section) and a separation zone (the uncoated section). The pre-concentration zone acts as an open-tubular ion-exchange column, which is used for adsorption of analyte anions. It is coated with nanometer-sized latex particles, functionalized with quaternary ammonium groups. Elution of the adsorbed anions is performed with a compositional gradient of increasing eluotropic strength, formed from a transient isotachophoretic boundary between two electrolytes.

Optimization of the concentration of the weak electrolyte and the method used to introduce it to the capillary prior to application of the voltage were crucial to obtain highly efficient 


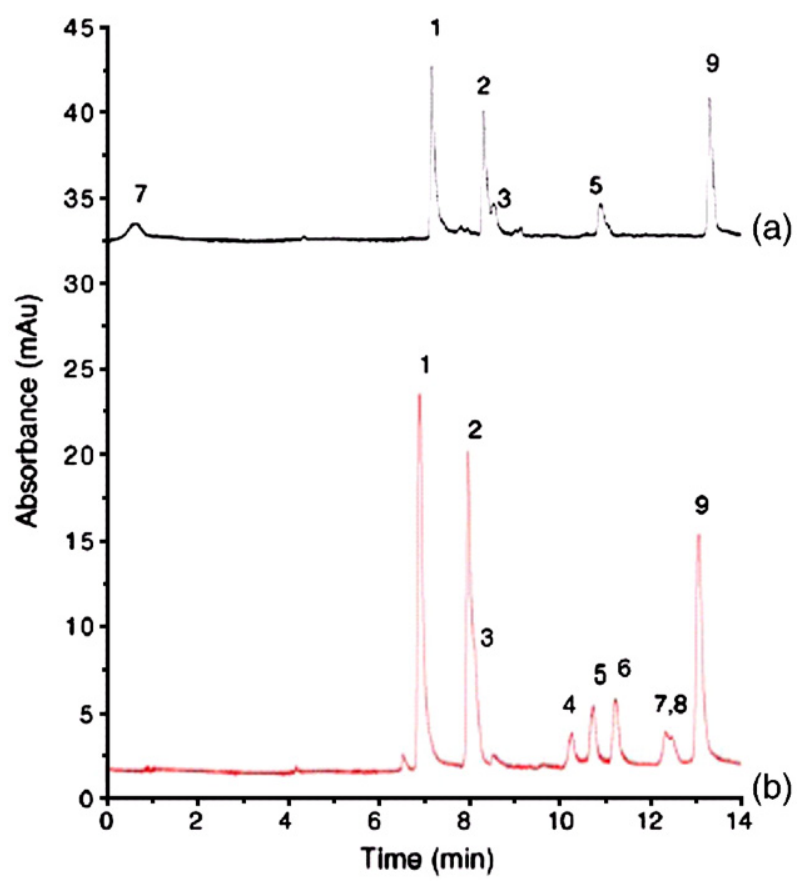

Fig. 2. Comparison of (a) pre-concentrated trace organic anions and (b) a standard. EC injection on the same latex-coated monolith, attached to a CE capillary. Injection: (a) pre-concentration step: 12 bar, $5 \mathrm{~min}, 50 \mathrm{nM}$ (1) sulfosalicylate, (2) naphthalene trisulfonate, (3) phthalate, (4) toluene sulfonate, (5) salicylate, (6) benzoate, (7) toluate, (8) 4-hydroxybenzoate, (9) naphthalene sulfonate; voltage, $-30 \mathrm{kV}$; temperature, $25{ }^{\circ} \mathrm{C}$; UV detection, $214 \mathrm{~nm}$. (b) $950 \mathrm{mbar}, 0.1$-min flush of $0.5 \mathrm{mM}$ organic anions, as above. Other conditions as in (a). Extracted from reference [15].

separations. Using an optimized method, a 100-min pressure injection allowed 40 capillary volumes of sample to be injected and gave an increase in sensitivity by a factor of 900 over standard CE hydrodynamic injection, without any loss in resolution and separation efficiency, and provided sub-ppb detection limits for $\mathrm{NO}_{3}^{-}, \mathrm{CrO}_{4}^{2-}$, and $\mathrm{MoO}_{4}^{2-}$. A more practical method, based on a 10-min injection, enabled a 100-fold increase in sensitivity to be achieved for $\mathrm{Br}^{-}, \mathrm{NO}_{3}^{-}, \mathrm{I}^{-}, \mathrm{CrO}_{4}^{2-}$, and $\mathrm{MoO}_{4}^{2-}$ within a total analysis time of $25 \mathrm{~min}$. This method was used to determine the concentration of $\mathrm{NO}_{3}^{-}$in Antarctic ice cores, where the CE method allowed a 100-fold reduction in sample size.

Haddad's group [15] has also explored capillary electrochromatography of inorganic and organic species, performed on a latex-coated monolithic methacrylate column. This highlighted the presence of mixed-mode interactions resulting from the incomplete coverage of latex particles on the monolithic surface. Analyte pre-concentration prior to separation resulted in compression of the analyte zone by a factor of 300 . Improvement in the limit of detection of up to 10400 times could be achieved by the pre-concentration step. The methods had limits of detection $(\mathrm{S} / \mathrm{N}=3)$ ranging between 1.5 and $12 \mathrm{nM}$ for the organic anions studied. Fig. 2 shows an example where a $50 \mathrm{nM}$ sample of organic anions had been pre-concentrated on an 8-cm, 75- $\mu \mathrm{m}$ i.d. latex-coated monolithic column. The short pre-concentrator column was attached to a PDDAC-coated separation capillary. The weak electrolyte (WE) was $50 \mathrm{mM}$
$\mathrm{NaF}$, which was used to selectively remove toluene sulfonate, benzoate, and 4-hydroxybenzoate from the loaded sample prior to separation. Fig. 2(b) shows a standard CEC separation, performed with only the strong electrolyte (SE). Peak 7 (toluate) shows greatly altered retention times between the two Figures, as it possesses a low ion-exchange selectivity coefficient. It was eluted chromatographically from the pre-concentrator during the introduction of the weak electrolyte. Once the voltage had been applied, toluate migrated past the detector, sooner than after a standard CE injection on the same column. Quantitative aspects, often forgotten when designing new devices, have also been considered [16]. Linear calibration curves were obtained for aqueous mixtures of bromide, nitrite, nitrate, and iodide, but when real ocean water, with high levels of chloride, was tested, recoveries of all analytes except iodide were reduced significantly. The pre-concentration method was applied to the determination of iodide in open ocean water and provided a limit of detection of $75 \mathrm{pM}(9.5 \mathrm{ng} / \mathrm{L})$, calculated at a signal-tonoise ratio of 3 . The relative standard deviations for migration time and peak area for iodide were 1.1 and $2.7 \%$, respectively.

\section{Cation exchange}

Zhang et al. [17] have also used a dual-layer ion-exchange latex-coated column for cations in open-tubular ion-exchange CEC. After pre-concentration, the analyte cations were eluted with a transient isotachophoretic gradient and separated by $\mathrm{CE}$. The latex double layer was established by first coating the negatively charged wall of the capillary with a layer of cationic quaternary ammonium anion-exchange latex particles $(60 \mathrm{~nm}$, Dionex AS5A), and then coating a layer of anionic sulfonated cation-exchange latex particles (300 nm, Dionex CS3) on the underlying AS5A layer. Using an 8-cm length of coated capillary, combined with a $72-\mathrm{cm}$ length of untreated capillary, a method for on-line pre-concentration and separation of monovalent organic bases, alkali metal ions, and alkalineearth metal ions by CE was developed. Recoveries for alkali metal ions and for alkaline-earth cations were $71-75 \%$. In all cases, recoveries were reproducible with RSDs being less than $6.2 \%$.

In another study, an on-line pre-concentration method, based on ion-exchange SPE was developed for the determination of cationic analytes in capillary electrophoresis. The pre-concentration/separation system consisted of a pre-concentration capillary, bonded with a carboxyl cation-exchange stationary phase, a separation capillary for CE and a T-joint interface of the capillaries. Two capillaries were connected closely inside a 0.3 mm i.d. polytetrafluoroethylene tube with a side opening and fixed together by the interface. The preparations of the preconcentration capillaries and interface were described in detail in this paper. The on-line pre-concentration and separation procedure of the analysis system included washing and conditioning the capillaries, loading analytes, filling with buffer solution, eluting analytes, and separating them by $\mathrm{CE}$. The proposed method enhanced the detection sensitivity of $\mathrm{CE} / \mathrm{UV}$ ca. 5000 times for propranolol and metoprolol over normal electrokinetic injection. The detection limits of propranolol and 


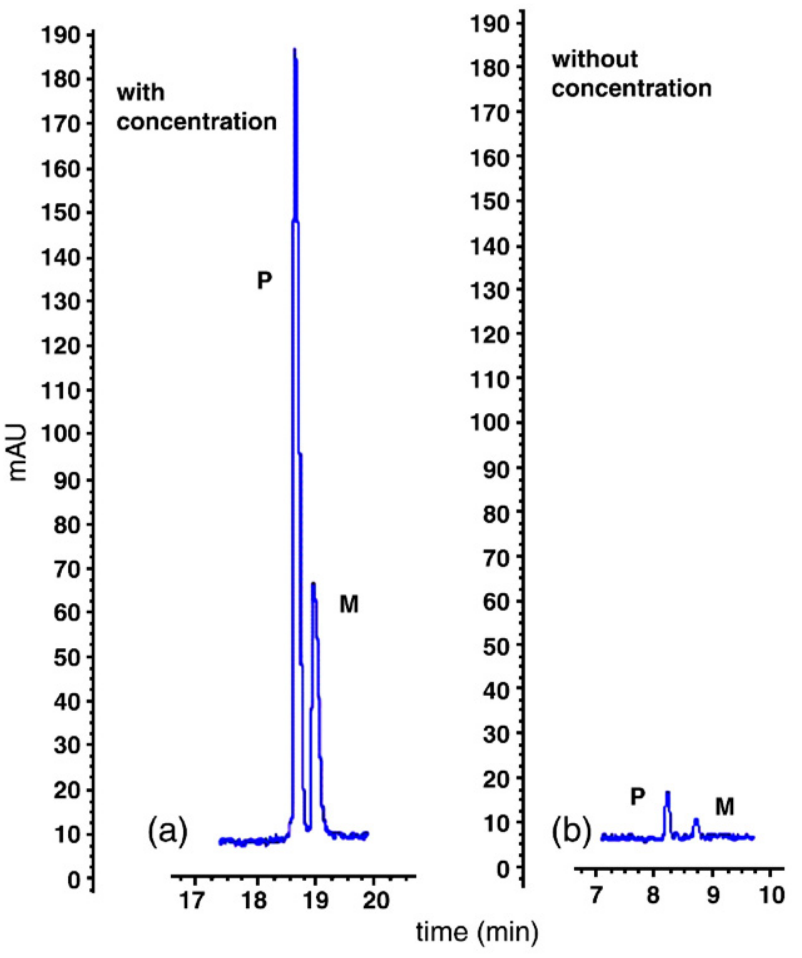

Fig. 3. Electropherograms of propranolol (P) and metoprolol (M) with (a) and without (b) on-line pre-concentration. Conditions: (a) the sampling flow-rate and loading time were $0.03 \mathrm{~mL} / \mathrm{min}$ and $10 \mathrm{~min}$, respectively; the eluent was $2.0 \mathrm{~mol} / \mathrm{L} \mathrm{NH} \mathrm{NH}_{4} \mathrm{Cl}$, injected at $10 \mathrm{kV}$ for $10 \mathrm{~s}$; the running buffer solution was $100 \mathrm{mmol} / \mathrm{L} \mathrm{NaOAc} / \mathrm{HOAc}(\mathrm{pH} 4.0)$; the separation voltage was $18 \mathrm{kV}$; and the UV detection wavelength was $214 \mathrm{~nm}$. (b) The sample solution contained $32 \mathrm{mg} / \mathrm{L}$ propranolol and $80 \mathrm{mg} / \mathrm{L}$ metoprolol; the electrokinetic injection was carried out at $6 \mathrm{kV}$ for $8 \mathrm{~s}$; separation voltage was $15 \mathrm{kV}$; The separation capillary, running buffer solution and detection wavelength were the same as in (a). Extracted from reference [18].

metoprolol were 0.02 and $0.1 \mu \mathrm{g} / \mathrm{L}$, respectively, with the proposed method, whereas with conventional electrokinetic injection these were 0.1 and $0.5 \mathrm{mg} / \mathrm{L}$ [18]. Fig. 3 shows the electropherograms of propanolol and metoprolol with and without pre-concentration.

\section{4. $\mathrm{C}-18$}

A method was optimized and evaluated for the purity control of the biologically active synthetic peptide fas-F (a 28-residue fragment of fasciculin-1) and applied to purity profiling of angiotensin I, oxytocin, bradykinin, and luteinizing-hormonereleasing hormone with an in-line concentrator cartridge, packed with silica-based C-18 particles and coupled near the inlet of the capillary [19]. Fig. 4 shows a schematic representation of this kind of pre-concentrator setup. The proposed method allowed the pre-concentration and separation of impurities with greater selectivity and higher sensitivity (100- to 200-fold) with respect to CE without in-line pre-concentration. Moreover, validation parameters of the method were calculated to make the method useful for quality control.

SPE and CE have been coupled on-line via a T-split interface, which provides hydrodynamic injection of the SPE eluate by flow-splitting [20]. The interface allows sample preconcentration independent of the CE separation and prevents sample matrix and washing solvents from entering the separation capillary. The effect of the T-split interface on CE efficiency was examined, using enkephalin peptides as model compounds. Plate numbers up to 120,000 were obtained, using a sample volume of $250 \mu \mathrm{L}$ and a split ratio of 1:40. UV absorbance concentration limits of detection $(\mathrm{S} / \mathrm{N}=3)$ were ca. $5 \mathrm{ng} / \mathrm{mL}$. For $250-\mu \mathrm{L}$ injections of $100 \mathrm{ng} / \mathrm{mL}$, the relative standard deviation $(n=5)$ of peak area was lower than $10 \%$ [21].

A miniaturized membrane-based SPE cartridge with a C-18impregnated Empore extraction disk was attached to the $\mathrm{CE}$ capillary near the injection end to improve the sensitivity of an original sheathless CE/MS design [22]. The system was applied to the analysis of proteomic samples, including isotope-coded affinity-tag labeling (ICAT)-labeled, membrane, solution, and in-gel-digested proteins. Despite the emphasis on proteomic applications in this paper, the system can also be adapted for concentration, separation, and analysis of other types of analytes, including small molecules.

Sandra et al. [23] were able to analyze peptides and glycopeptides in the high-picomolar range by CE/MS. They constructed a short pre-concentrator, placing a C-18 bed into the capillary. This retained the analytes during the sample load step, and they were subsequently released with an organic eluent. Stoggl et al. [24] performed baseline separations of biologically relevant flavonoids by packing 3- $\mu \mathrm{m} \mathrm{C}-18$ material into a $100-$ $\mu \mathrm{m}$ i.d. capillary. Other procedures for peptide clean-up and preconcentration in $\mathrm{CE}$ have been been reviewed recently by Kasicka [25].

\section{Immuno-affinity}

Immuno-affinity sample preparation techniques are based upon molecular recognition. Thanks to the high affinity and high selectivity of the antigen/antibody interaction, they have been shown to be a unique tool for sampling. Immuno-affinity sample preparation methods include the widely used immunoaffinity extraction sorbents (so-called immuno-sorbents), as well as membrane-based or ultrafiltration techniques. Hennion and Pichon [26] reviewed the new developments and applications with emphasis on (i) antigen/antibody interactions, (ii) their importance for the properties and use of immuno-sorbents,

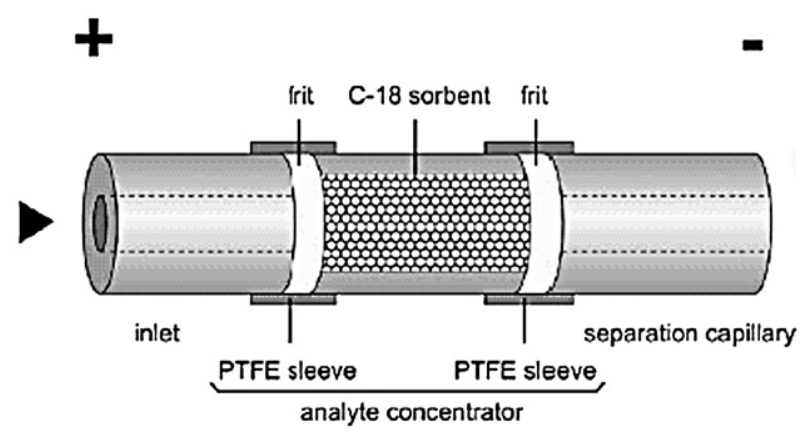

Fig. 4. Schematic representation of the analyte pre-concentration cartridge. Extracted from Ref. [19]. 

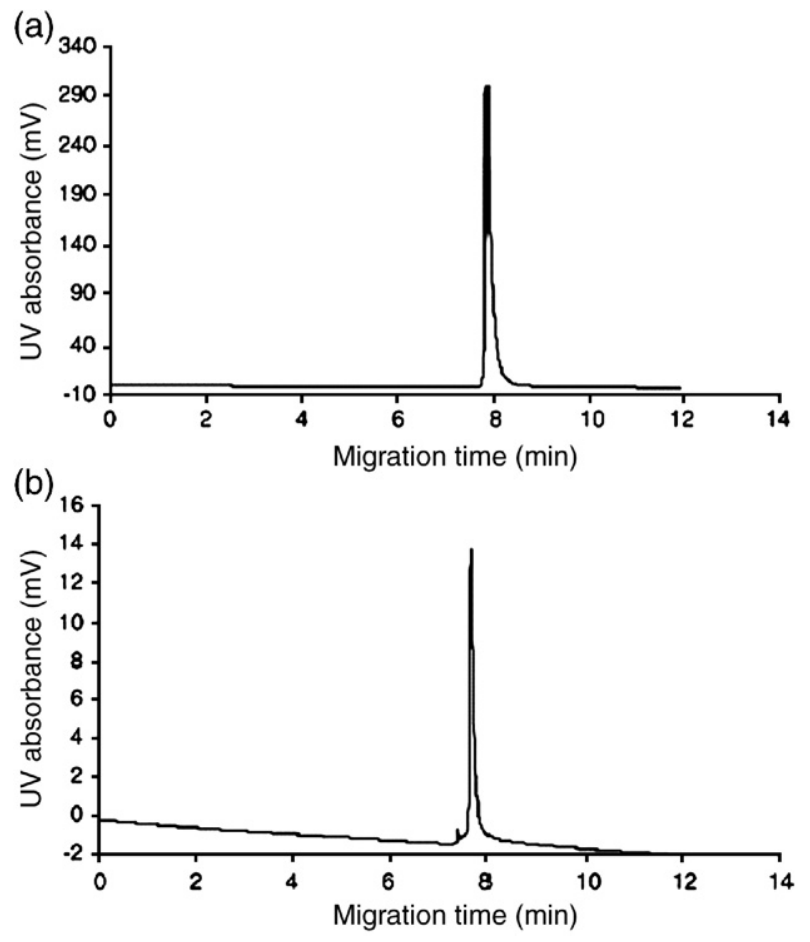

Fig. 5. Electropherograms, demonstrating on-line pre-concentration/CE of IgG from human serum. Experimental conditions: $64 \mathrm{~cm}(53 \mathrm{~cm}$ to detector $) \times 75 \mu \mathrm{m}$ i.d. fused-silica capillary; $1.5 \mathrm{~cm}$ protein $\mathrm{G}$ monolithic pre-concentrator; $50 \mathrm{mM}$ formic acid (1.0 bar, $0.3 \mathrm{~min}$ ) elution buffer; $12.5 \mathrm{mM}$ ammonium formate/ formic acid ( $\mathrm{pH}$ 7.6) separation buffer; $+15 \mathrm{kV}$ applied separation voltage; UVdetection at $214 \mathrm{~nm}$. (A) 500 times diluted human serum (ca. $6 \mu \mathrm{L}$ volume sampled) and (B) 65,000 times diluted human serum (ca. $28 \mu \mathrm{L}$ volume sampled). Extracted from Ref. [27].

(iii) multi-residue extractions, (iv) the on-line coupling to chromatographic or electrophoretic separations, and (v) the high potential for improving MS detection.

One such method is immuno-affinity CE. This emerging hybrid technology employs two powerful techniques, coupled on-line for the direct and rapid determination of analytes present in biological fluids. The first technique, immuno-affinity, is used for the selective extraction of a molecule present in a complex matrix, utilizing a micro-scale chamber affinity device. An analyte (affinity target), present in serum or urine, is captured by an immobilized molecular recognition antibody molecule (affinity ligand), bound to a solid support constituent (glass beads or an appropriate porous structure) of a microchamber affinity device. The second technique, CE, is used for the high-resolution analytical separation of the purified and concentrated affinity target material after elution from the micro-chamber affinity device.

The analysis of proteins in biological fluids by $\mathrm{CE}$ is of interest in clinical chemistry. However, due to low analyte concentrations and poor concentration limits of detection (CLOD), protein analysis by this technique is frequently challenging. To accomplish this, the development of an online Protein G monolithic pre-concentrator/CE device has been proposed [27]. To generate active groups for protein immobilization, glycidyl methacrylate (GMA) was used to prepare polymer monoliths. A 1.5 - to 2 -cm monolith was cast inside a $75-\mu \mathrm{m}$ i.d. fused-silica capillary that had previously been coated with alternating layers of negatively (dextran) and positively (polybrene) charged polymers. Protein G was covalently bound to GMA. Monoliths from different formulations were prepared and evaluated for binding capacity to optimize the monolith formulation for protein pre-concentration. The physical properties of the column considered best for pre-concentration were determined by mercury intrusion porosimetry. The monolith had a low flow-resistance and was macroscopically homogeneous. The effectiveness of the monolith to rapidly preconcentrate proteins at flow-rates as high as $10 \mu \mathrm{L} / \mathrm{min}$ was demonstrated, using a 1.8- $\mu \mathrm{M}$ IgG solution. This system proved effective for on-line sample extraction, clean-up, pre-concentration, and $\mathrm{CE}$ of $\mathrm{IgG}$ in human serum. IgG from diluted (500 and 65,000 times) human serum samples was successfully analyzed, using this system. Fig. 5 shows the electropherograms obtained with this technique from two diluted human serum samples. The method can be applied to the on-line preconcentration and analysis of any protein for which an antibody is available.

A simple solid-phase micro-extraction device was fabricated for use in on-line immuno-affinity $\mathrm{CE}$. The device, designed in the form of a four-part cross-shaped configuration, includes a large-bore tube to transport samples and washing buffers and a small-bore fused-silica capillary for the separation of analytes. At the intersection of the transport and separation tubes, a small cavity was fabricated, termed the analyte concentrator/microreactor, which contains four porous walls or semi-permeable membranes (one for each, inlet and outlet of the tubes) permitting the confinement of beads or suitable microstructures. The surface of the beads in the analyte concentrator carried a molecular recognition adsorbing chemical or affinity ligand material. The improved cruciform configuration of the analyte concentrator/micro-reactor device, designed for use in on-line immuno-affinity $\mathrm{CE}$, enables it to specifically trap, enrich, and elute an analyte from any biological fluid or tissue sample extract without any sample pretreatment, except filtration, centrifugation, and/or dilution and allowing the separation and characterization of target analyte(s) with improved speed, sensitivity, and lower cost than existing techniques. As a model system, Fab' fragments, derived from a purified immunoglobulin $\mathrm{G}$ ( $\mathrm{IgG}$ ) antibody were covalently bound to controlled-porosity glass and used as constituents of the analyte/micro-reactor device. The high-specificity polyclonal antibodies employed in these experiments were individually raised against the acidic nonsteroidal anti-inflammatory drugs, ibuprofen and naproxen, and the neuropeptides, angiotensin II and neurotensin. These compounds, which were present in simple and complex matrices were captured by and eluted from the analyte concentrator/micro-reactor,

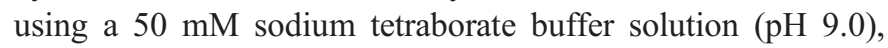
followed by a 100-nL plug of $300 \mathrm{mM}$ glycine buffer ( $\mathrm{pH} 3.4)$. Two analyte concentrators were tested independently: one containing Fab' fragments derived from antibodies raised against ibuprofen and naproxen; the other containing Fab' fragments derived from antibodies raised against angiotensin II 
and neurotensin. Each resulting electropherogram demonstrated the presence of two eluted materials in less than $20 \mathrm{~min}$. Immuno-affinity CE, performed in a cruciform structure, was simpler and faster than previously reported in the literature with on-line micro-extraction devices designed in a linear arrangement [28]. The new concentration/separation system operated consistently for many runs, maintaining reproducible migration times and peak areas for every analyte studied.

A completely different approach has been developed by Rios et al. [29]. Enzymes immobilized on the inner surface of an electrophoretic capillary were used to increase sensitivity and resolution in CE. Sensitivity is enhanced by inserting a piece of capillary, containing the immobilized enzyme, into the main capillary, located before the detector, in order to transform the analyte into a product with a higher absorptivity. This approach was used to determine ethanol. In order to improve resolution, capillary pieces containing immobilized enzymes were inserted at various strategic positions along the electrophoretic capillary. On reaching the enzyme, the analyte was converted to a product with a high electrophoretic mobility, the migration time for which was a function of the position of the enzyme reactor. This technique was applied to the separation and determination of acetaldehyde and pyruvate. Finally, the proposed method was validated with the determination of ethanol, acetaldehyde, and pyruvate in beer and wine samples.

The enzymatic reaction, which usually involves an NADHdependent dehydrogenase, provides a vast field of applications. In fact, more than 300 dehydrogenase enzymes that are selective to substrates of great analytical interest in clinical, environmental and food chemistry have been reported.

A chip-based capillary electrophoresis system has been designed for rapidly measuring the concentrations of inflammatory cytokines in the cerebrospinal fluid of patients with head trauma [30]. Isolation of the reactive cytokines was achieved by immuno-affinity capture, using a panel of six immobilized antibodies, directly attached to the injection port of the chip. The captured cytokines were labeled in situ with a red lightemitting laser dye and electro-eluted into the separation channel. Separation of the isolated cytokines was achieved by electrophoresis in under $2 \mathrm{~min}$ with quantification of the resolved peaks by on-line laser-induced fluorescence and integration of each peak area. Comparison of the results with commercially available high-sensitivity immunoassays demonstrates that the chip-based assay provides a fast, accurate procedure for studying the concentrations of these analytes in complex biological materials. The degree of accuracy and precision achieved by the chip-based $\mathrm{CE}$ is comparable to conventional immunoassays, the system being able to analyze between 10 and 12 samples per hour. With the ever-expanding array of antibodies that are commercially available, this chipbased system can be applied to a wide variety of different analyses.

An on-line pre-concentration system, comprising a small piece of absorbing polymer at the beginning of the capillary, traps the analytes in a non-selective manner when several capillary volumes of sample are injected. After desorption, electrophoretic separation of the concentrated analytes takes place in the capillary. In combination with low-wavelength UV detection, good concentration sensitivity was obtained, and the complete system was evaluated and validated for detection of a number of model peptides in the low-nanomolar region. Besides for concentration purposes, this system has proved to be a good on-line desalting system for microliter sample volumes. Obviously, in combination with MS detection and a sheathless interface, more selectivity can be achieved.

An earlier developed CE system with an on-capillary adsorptive phase [31] was investigated for its suitability for the quantitation of low concentrations of angiotensin II and gonadorelin in plasma. Off-line SPE was used for sample preparation. The on-line pre-concentration CE system allowed multiple capillary volumes of sample solution to be injected, increasing the concentration sensitivity of CE 3-4 orders of magnitude. Furthermore, the possible influence of matrix salts was eliminated by employing a rinsing step after sample application. Using short-wavelength UV detection, reproducibility and linearity in the low nanomolar range were satisfactory [32]. The capillary could be efficiently regenerated, using a programmed between-run rinsing procedure, thus allowing 20-30 large injections of sample extracts. Coating of the capillary improved the robustness of the method. Mass spectrometric detection via a previously reported sheathless interface [33] increased the selectivity and sensitivity substantially. Recommendations were provided for the sample preparation process, the most critical part of the system. Further purification of the sample was required to allow the loading of larger sample volumes and to optimize the robustness of the system.

\section{Miscellaneous}

An on-line interface between the fiber-in-tube SPME and CE has been developed [34], and the pre-concentration and separation of four tricyclic antidepressant (TCA) drugs, amitriptyline, imipramine, nortriptyline, and desipramine, were performed with the coupled system. Under optimized condition, a better extraction performance than with conventional in-tube SPME was obtained, even though the extraction medium was much shorter. The results clearly indicated that the fiber was working effectively as an extraction medium. For the separation of these four TCAs, capillary electrophoretic separation with $\beta$-cyclodextrin as the buffer additive has been employed, and the application of the system to the analysis of complex sample mixtures in a biological matrix was also demonstrated.

A novel in-line method was presented for the extraction and pre-concentration of amino acids with a sol/gel-coated column, coupled to a conventional UV/visible detector. It did not require any additional modification of the commercially available standard CE instrument. Extraction, stacking, and focusing techniques were used in the pre-concentration procedures. Sol/ gel coatings were created by using $N$-octadecyldimethyl[3(trimethoxysilyl)proply]ammonium chloride (C-18-TMS) in the coating sol solutions. Due to the presence of a positively charged quaternary ammonium moiety in C-18-TMS, the 
resulting sol/gel coating carried a positive charge. For extraction, the $\mathrm{pH}$ of the samples was adjusted so as to impart a net negative charge to the amino acids. A long plug of sample was then passed through the sol/gel-coated capillary to facilitate extraction via electrostatic interaction between the positively charged sol/gel coating and the negatively charged amino acid molecules. Focusing of the extracted amino acids was accomplished through desorption of the extracted amino acids by local $\mathrm{pH}$ change. Two different methods were described. Both methods showed excellent extraction and pre-concentration effects. Pre-concentration results obtained with sol/gelcoated columns were compared with the $\mathrm{CE}$ analysis performed on bare fused-silica columns with traditional sample injections [35]. The procedure provided a 150,000-fold enrichment effect for alanine. The two methods showed acceptable repeatability in terms of both peak height and migration time.

An efficient on-line pre-concentration method by LPME prior to CE has been tested [36]. A drop of the basic acceptor phase, hanging at the capillary inlet tip, was covered with a thin organic film. When the drop was placed in an acidic sample donor phase, acidic analytes were extracted into the acceptor phase through the organic film. The pre-concentrated sample was then separated using a running buffer identical to the acceptor phase. A concentration ratio of 3 orders of magnitude was obtained for fluorescein with 30-min extraction. This simple technique consumed very little solvent, and no additional equipment was required. The small-volume drop matched the small injection volume in CE. Prior to the CE experiments, three approaches of bead immobilization for CEC column preparation in a capillary were examined for SPE [37]. The three approaches included a packed column with a single frit, a packed column with an inlet and outlet frit, and an entrapped column, where beads were immobilized within an organic polymer. A direct comparison of SPE/pre-concentration of 4,4-difluoro-1,3,5,7,8-pentamethyl-4-bora-3a,4a-diaza-sindacene and 4,4-difluoro-5,7-dimethyl-4-bora-3a,4a-diaza-sindacene-3-propionic acid with a 2 -cm-long bed showed that the entrapped column yielded the best performance in terms of reproducibility and robustness. A 0.5 -cm-long entrapped bed exhibited high mechanical strength and was able to withstand $>4400$ psi. The entrapped bed was used to pre-concentrate progesterone and beta-estradiol, providing signal enhancements of $>600$.

$\mathrm{Wu}$ and Umeda [38] described the in-capillary preconcentration of proteins with the use of a cellulose acetatecoated porous joint. The capillary wall near the inlet end of a capillary was made porous by HF etching. During the etching process, a voltage was applied across the capillary wall and the electric current was monitored. As the current passed through the capillary wall, it became porous. A solution of cellulose acetate in acetone was added to the etched porous joint. After the acetone was removed by evaporation, a cellulose acetatecoated porous joint was formed. To pre-concentrate the protein ions, an electric voltage was applied between the inlet end of the capillary and the coated porous joint. The protein ions electromigrated to the porous joint but could not pass through it, while the buffer ions could easily pass through the joint. After allowing a certain amount of time for protein pre-concentration, a separation voltage was applied across the two ends of the capillary, and normal CE was carried out. The pre-concentration factors for cytochrome $c$, lysozyme, ribonuclease, and chymotrypsinogen were $65,155,705$, and 800 , respectively. The cellulose acetate-coated porous joint was shown to be strong and stable over time, and it was used to analyze traces of proteins and macromolecules in biological samples. Based on the same size-exclusion principle, a simple on-line preconcentration method of protein for $\mathrm{CE}$ with a cellulose acetate (CA)-coated porous membrane was proposed [39]. The CA membrane was fabricated at one of the ends of the column to allow the passage of buffer ions but exclude larger protein molecules. Protein sample was continuously electro-kinetically loaded and trapped by the membrane. When injection was completed, the direction of the electric field was switched, and the trapped proteins were separated by conventional CE. Bovine serum albumin (BSA) was used as a model protein, and signal enhancement of 550-fold with 15 min injection time was achieved.

In summary, new developments in CE enable enhancement of the detection sensitivity and simultaneous sample clean-up. On-line and in-line sample pre-concentration with SPE-derived systems benefit from 2-D selectivity, which is especially useful for protein analysis and MS coupling. Nevertheless, the amount of sample that can be loaded when working with real matrices, as well as the coupling of the different devices to the $\mathrm{CE}$ capillary and the quantitative aspects are still problems needing to be solved.

\section{References}

[1] Guzman NA, Trebilcock MA, Advis JP. The use of a concentration step to collect urinary components separated by capillary electrophoresis and further characterization of collected analytes by mass spectrometry. J Liq Chromatogr 1991;14:997-1015.

[2] Veraart JR, Lingeman H, Brinkman UA. Coupling of biological sample handling and capillary electrophoresis. J Chromatogr A 1999;856:483-514.

[3] Bonneil E, Waldron KC. On-line solid-phase pre-concentration for sensitivity enhancement in capillary electrophoresis. J Capillary Electrophor 1999;6:61-73.

[4] Osbourn DM, Weiss DJ, Lunte CE. On-line pre-concentration methods for capillary electrophoresis. Electrophoresis 2000;21:2768-79.

[5] Guzman NA, Stubbs RJ. The use of selective adsorbents in capillary electrophoresis-mass spectrometry for analyte pre-concentration and micro-reactions: a powerful three-dimensional tool for multiple chemical and biological applications. Electrophoresis 2001;22:3602-28.

[6] Stroink T, Paarlberg E, Waterval JC, Bult A, Underberg WJ. On-line sample pre-concentration in capillary electrophoresis, focused on the determination of proteins and peptides. Electrophoresis 2001;22:2375-83.

[7] Jonsson JA, Mathiasson L. Membrane-based techniques for sample enrichment. J Chromatogr A 2000;902:205-25.

[8] Guzman NA. Multi-dimensional electrophoresis apparatus, United States Patent Application 10/728,499 (2003).

[9] Guzman NA. Immuno-affinity capillary electrophoresis applications of clinical and pharmaceutical relevance. Anal Bioanal Chem 2004;378:37-9.

[10] Guzman NA, Phillips TM. Immuno-affinity CE for proteomics studies. Anal Chem 2005;77:60A-7A.

[11] Kelly RT, Li Y, Woolley AT. Phase-changing sacrificial materials for interfacing micro-fluidics with ion-permeable membranes to create on-chip pre-concentrators and electric field gradient focusing micro-chips. Anal Chem 2006;78:2565-70. 
[12] Breadmore MC, Palmer AS, Curran M, Macka M, Avdalovic N, Haddad PR. On-column ion-exchange pre-concentration of inorganic anions in open tubular capillary electrochromatography with elution using transientisotachophoretic gradients. 3. Implementation and method development. Anal Chem 2002;74:2112-8.

[13] Breadmore MC, Boyce M, Macka M, Avdalovic N, Haddad PR. Analyst 2000;125:799-802.

[14] Breadmore MC, Macka M, Avdalovic N, Haddad PR. On-capillary ionexchange pre-concentration of inorganic anions in open-tubular capillary electrochromatogrpahy with elution using transient-isotachophoretic gradient. 2. Characterization of the isotachophoretic gradient. Anal Chem 2001;73:820-8.

[15] Hutchinson JP, Macka M, Avdalovic N, Haddad PR. On-line preconcentration of organic anions in capillary electrophoresis by solid-phase extraction using latex-coated monolithic stationary phases. J Chromatogr A 2006;1106:43-51.

[16] Hutchinson JP, Zakaria P, Bowie AR, Macka M, Avdalovic N, Haddad PR. Latex-coated polymeric monolithic ion-exchange stationary phases. 1. Anionexchange capillary electrochromatography and in-line sample pre-concentration in capillary electrophoresis. Anal Chem 2005;77:407-16.

[17] Zhang S, Macka M, Haddad PR. Preparation and characterisation of duallayer latex-coated columns for open-tubular capillary electrochromatographic pre-concentration of cations combined in-line with their separation by capillary electrophoresis. Electrophoresis 2006;27:1069-77.

[18] Zhang ZX, He YZ. On-line cation-exchange pre-concentration and capillary electrophoresis coupled by tee joint interface. J Chromatogr A 2005;1066:211-8.

[19] Vizioli NM, Rusell ML, Carducci CN. On-line pre-concentration capillary electrophoresis for purity profiling of synthetic peptides. Anal Chim Acta 2004;514:167-77.

[20] Tempels FW, Teeuwsen J, Kyriakou IK, Theodoridis G, Underberg WJ, Somsen GW, et al. Chromatographic pre-concentration coupled on-line to capillary electrophoresis via a tee-split interface. J Chromatogr A 2004;1053:263-8.

[21] Tempels FW, Underberg WJ, Somsen GW, de Jong GJ. Chromatographic pre-concentration coupled to capillary electrophoresis via an in-line injection valve. Anal Chem 2004;76:4432-6.

[22] Janini GM, Zhou M, Yu LR, Blonder J, Gignac M, Conrads TP, et al. Oncolumn sample enrichment for capillary electrophoresis sheathless electrospray ionization mass spectrometry: evaluation for peptide analysis and protein identification. Anal Chem 2003;75:5984-93.

[23] Sandra K, Lynen F, Devreese B, Van Beeumen J, Sandra P. On-column sample enrichment for the high-sensitivity sheath-flow CE-MS analysis of peptides. Anal Bioanal Chem 2006;385:671-7.

[24] Stoggl WM, Huck CW, Stecher G, Bonn GK. Capillary electrochromatography of biologically relevant flavonoids. Electrophoresis 2006;27:787-92.
[25] Kasicka V. Recent developments in capillary electrophoresis and capillary electrochromatography of peptides. Electrophoresis 2006;27:142-75.

[26] Hennion MC, Pichon V. Immuno-based sample preparation for trace analysis. J Chromatogr A 2003;1000:29-52.

[27] Armenta JM, Gu B, Humble PH, Thulin CD, Lee ML. Design and evaluation of a coupled monolithic pre-concentrator-capillary zone electrophoresis system for the extraction of immunoglobulin $\mathrm{G}$ from human serum. J Chromatogr A 2005;1097:171-8.

[28] Guzman NA. Improved solid-phase micro-extraction device for use in on-line immuno-affinity capillary electrophoresis. Electrophoresis 2003;24:3718-27.

[29] Simonet BM, Rios A, Valcarcel M. Analytical potential of enzyme-coated capillary reactors in capillary zone electrophoresis. Electrophoresis 2004;25:50-6.

[30] Phillips TM. Rapid analysis of inflammatory cytokines in cerebrospinal fluid using chip-based immuno-affinity electrophoresis. Electrophoresis 2004;25:1652-9.

[31] Waterval JC, Hommels G, Teeuwsen J, Bult A, Lingeman H, Underberg WJ. Quantitative analysis of pharmaceutically active peptides using oncapillary analyte pre-concentration transient isotachophoresis. Electrophoresis $2000 ; 21: 2851-8$.

[32] Waterval JC, Hommels G, Bestebreurtje P, Versluis C, Heck AJ, Bult A, et al. Capillary electrophoretic bioanalysis of therapeutically active peptides with UV and mass spectrometric detection after on-capillary pre-concentration. Electrophoresis 2001;22:2709-16.

[33] Waterval JC, Bestebreurtje P, Lingeman H, Versluis C, Heck AJ, Bult A, et al. Robust and cost-effective capillary electrophoresis-mass spectrometry interfaces suitable for combination with on-line analyte preconcentration. Electrophoresis 2001;22:2701-8.

[34] Jinno K, Kawazoe M, Saito Y, Takeichi T, Hayashida M. Sample preparation with fiber-in-tube solid-phase micro-extraction for capillary electrophoretic separation of tricyclic antidepressant drugs in human urine. Electrophoresis 2001;22:3785-90.

[35] Li W, Fries D, Alli A, Malik A. Positively charged sol-gel coatings for online pre-concentration of amino acids in capillary electrophoresis. Anal Chem 2004;76:218-27.

[36] Choi K, Kim Y, Chung DS. Liquid-phase micro-extraction as an on-line preconcentration method in capillary electrophoresis. Anal Chem 2004;76:855-8.

[37] Xie R, Oleschuk R. Capillary-based solid-phase extraction with columns prepared using different bead trapping methods. Electrophoresis 2005;26:4225-34.

[38] Wu XZ, Umeda R. In-capillary pre-concentration of proteins for capillary electrophoresis using a cellulose acetate-coated porous joint. Anal Bioanal Chem 2005;382:848-52.

[39] Yang B, Zhang F, Tian H, Guan Y. On-line pre-concentration of protein in capillary electrophoresis with an end-column cellulose acetate-based porous membrane. J Chromatogr A 2006;1117:214-8. 